\title{
El POBLAMIENTO ROMANO EN TORNO A OSSET (San Juan de Aznalfarache, Sevilla)
}

\author{
EnRIQUe Ruiz Prieto \\ Luis-gethsemaní Pérez-Aguilar \\ Álvaro Gómez Peña \\ Livia Guillén RodRíGuez \\ Universidad de Sevilla
}

Recibido: 15/01/2014

Revisado: 27/02/2014
Aceptado: $16 / 03 / 2014$

Publicado: 20/05/2014

\section{RESUMEN}

En esta contribución se realiza un estudio del poblamiento rural romano en torno a Osset, comparando los datos existentes con otros ámbitos geográficos (p.e.la campiña sur del río Guadalquivir). Para la elaboración de esta síntesis se ha procedido a estudiar cada sitio arqueológico de los términos municipales de San Juan de Aznalfarache, Tomares, Castilleja de la Cuesta, Gines, Bormujos, Mairena del Aljarafe y Gelves, revisando la cronología de cada uno de ellos. El resultado es una propuesta diferente a las planteadas hasta el presente.
ABSTRAC

In this contribution a synthesis of Roman rural settlement around Osset is performed by comparing the existing data with other geographical areas (e.g. the southern countryside of the Guadalquivir River). The synthesis has been realized studying each archaeological site of the towns of Camas, Tomares, Castilleja de la Cuesta, Gines, Bormujos, Mairena del Aljarafe and Gelves, reviewing their chronologies. The results are different to other existing proposals until the present.
Palabras Clave

Aljarafe; Bajo Guadalquivir; Baetis; Asentamientos rurales; Arqueología del territorio.

\section{KEYWORDS}

Aljarafe; Lower Guadalquivir; Baetis; Rural Settlements; Landscape Archaeology.

eruizprieto@hotmail.com 


\section{INTRODUCCIÓN}

Entre los años 2010 y 2011, a algunos de los autores del presente artículo se nos encomendó la tarea de investigar distintos aspectos relativos al pasado del Aljarafe sevillano, y más concretamente de aquella zona próxima al actual municipio de Tomares (Gómez Peña et alii, 2011). Esta obra trataba de ser un estudio general que abarcaba casi todos los periodos históricos del citado entorno geográfico, incluida la fase romana desde el periodo republicano hasta el tardoantiguo. Muy pronto nos dimos cuenta de la necesaria revisión de los diferentes yacimientos arqueológicos que se han documentado en esta zona y es por ese motivo por lo que redactamos estas líneas.

Antes de profundizar en el tema se desea aclarar una cuestión no menos importante. La revisión de los sitios arqueológicos debe hacerse en función de trabajos de campo anteriores, dado que en la década de los ochenta y noventa del pasado siglo el Aljarafe Oriental experimentó una notable transformación en su geografía, imposibilitando la realización de nuevos estudios territoriales a nivel de superficie. La citada zona de estudio se caracteriza a día de hoy por un hecho relevante: los cascos urbanos de los distintos municipios del reborde oriental del Aljarafe vienen actuando como ciudades dormitorio de Sevilla, lo que ha conllevado un amplio desarrollo de las actividades constructivas con el fin de albergar a población procedente de la capital (Delgado Bujalance, 2004, 64-73). La intensidad de este proceso urbanístico desembocó en el denominado fenómeno de la conurbación, hecho que ha ocasionado que el entramado urbano de poblaciones cercanas se aúne y confunda paisajísticamente, no percibiéndose apenas el paso de una localidad a otra. Todo esto ha propiciado la destrucción sistemática de yacimientos hoy en día imposibles de estudiar.

\section{EsTADO DE LA CUESTIÓN}

Para aproximarnos históricamente al poblamiento ossetano se debe recurrir necesariamente a los trabajos de campo realizados por M. Ponsich (1974) y J. L. Escacena Carrasco (1980). De las dos campañas existentes la que mayor información aporta es precisamente la de este último, tanto por la cantidad de los materiales encontrados como por la descripción topográfica de los sitios.

Los citados trabajos se ciñen a la metodología y la técnica del momento en el que se desarrollaron.
No obstante, los avances experimentados por la disciplina arqueológica han transformado tales criterios. Por ejemplo, en el momento de su realización únicamente se calculaba una coordenada geográfica mediante el uso de un mapa a través del sistema Lambert. En la actualidad se tiende a tomar múltiples coordenadas con tecnología GPS con el objetivo de delimitar el propio yacimiento mediante la creación de un polígono. Este hecho impide a día de hoy tener en cuenta la variable extensión a la hora de interpretar las distintas categorías arqueológicas con el fin de aproximarse a la comprensión del territorio romano (cf. García Vargas et alii, 2002, 315; Garrido González, 2011, 292-312). Es por esta razón por la que se prefiere denominar a los sitios que aquí se analizan como asentamientos rurales.

A las anteriores intervenciones arqueológicas deben sumarse otras realizadas durante las décadas posteriores que complementan parcialmente a las ya citadas (Romo Salas y Vargas Jiménez, 1997; Vargas Jiménez y Romo Salas, 1999, 2002; Guisado Castejón et alii, 2010; Hunt Ortiz y Cordero Ruiz, 2010; Domínguez Berenjeno y Vera Fernández, 2011). Debe igualmente hacerse referencia a la publicación de G. Chic García y E. García Vargas (2004) relativa a los alfares romanos de la provincia de Sevilla, y en la que se hace alusión al Cerro de los Villares (Bormujos).

Con todo lo expuesto, resulta conveniente la elaboración de una nueva síntesis sobre la dinámica poblacional en torno a la ciudad romana de Osset que contemple la información de estos nuevos trabajos.

\section{ANÁLISIS POBLACIONAL}

En las siguientes líneas se pretende confrontar dos realidades territoriales distintas pero a su vez complementarias: las campiñas al sur del Guadalquivir y la zona que circunda a la antigua ciudad romana de Osset, en el reborde oriental del Aljarafe sevillano. Por tanto, debe tenerse siempre en cuenta que la diferencia a nivel de extensión territorial constituye un factor relevante respecto a los distintos resultados. Sin embargo, el análisis comparativo que se plantea puede resultar fructífero si de lo que se trata es de aterrizar sobre comportamientos más locales que de otra forma quedarían diluidos al alejarse la lupa con la que se observa el territorio. A razón de ello, con este ejercicio se confrontan dos muestras poblacionales desiguales con el objetivo de ver cómo dentro de procesos generales pueden observarse fenómenos más concretos y que deben ser igualmente explicados. 
Para comprender la dinámica poblacional de este entorno ribereño uno de los factores a considerar es el papel jugado por el río Guadalquivir, importante vía de comunicación fluvial en la Antigüedad (Abad Casal, 1975). Durante la protohistoria desembocaba a la altura de las ciudades de Caura (Coria del Río) y Orippo (Torre de los Herberos, Dos Hermanas), abriéndose a partir de aquí un golfo denominado por las fuentes clásicas Lacus Ligustinus. Los estudios geoarqueológicos han corroborado cómo a partir de época republicana (siglos III-I a.C.) el dinamismo fluvial fue desplazando la paleodesembocadura hacia Nabrissa (Lebrija) y Asta Regia (Mesas de Asta, Jerez de la Frontera), proceso que se ralentizó a partir del periodo tardorrepublicano teniendo lugar una cierta estabilidad. Sin embargo, el citado dinamismo se reactivó nuevamente a partir del siglo IV d.C., trasladándose paulatinamente la desembocadura y originándose un paisaje cenagoso y palustre en el antiguo entrante de mar: las Marismas del Guadalquivir (Arteaga Matute et alii, 1995; Barral Muñoz, 2009). La principal causa de esta colmatación fue el resultado de un incremento del arrastre de sedimentos a través del río debido al aumento de la erosión de los suelos fruto de una intensa antropización de los entornos fluviales durante los siglos precedentes.

¿Qué secuela tuvo todo este proceso para los asentamientos de los alrededores? E. García Vargas y J. Vázquez Paz (2012) han reflexionado sobre la evolución del poblamiento rural romano para una amplia zona de las campiñas al sur del Guadalquivir, en la margen izquierda de su cauce 1 . Durante el Alto Imperio Romano una importante parte de estos asentamientos comercializaban sus productos a través de una serie de afluentes que guardaban servidumbre al Baetis aguas arriba de Hispalis. Cuando el dinamismo fluvial volvió a acentuarse en cuanto al arrastre de sedimentos (siglo IV d.C.), la navegabilidad del Guadalquivir se vio seriamente afectada para el tramo que iba desde Sevilla a Córdoba. A razón de ello muchos de estos asentamientos fueron desapareciendo y el poblamiento se hizo menos disperso. Si se compara el número de yacimientos arqueológicos del siglo III con el del

1 El estudio de estos autores se circunscribe a los actuales términos municipales de Dos Hermanas, Marchena, Fuentes de Andalucía, el sur de La Luisiana, el suroeste de Écija, el sureste de La Campana y las partes de Carmona y de Alcalá de Guadaira que quedan entre Los Alcores y la vega del Corbones.
IV puede inferirse que el descenso de asentamientos rurales es prácticamente nulo, puesto que de 104 quedaron ocupados 101. La quinta centuria supuso, sin embargo, una etapa en la que la disminución de lugares volcados a la explotación agrícola se incrementó notablemente, ya que el número de entidades rurales documentadas es de 77 . Además, a lo largo de dicho siglo se produjo un fenómeno en el occidente romano que debió modificar profundamente el paisaje general de la Baetica: la progresiva desaparición de las villae clásicas como unidades elementales de ocupación y explotación agropecuaria del territorio (Chavarría Arnau, 2007). En las campiñas al sur del Guadalquivir dicho proceso se traduce igualmente en el abandono de asentamientos rurales, hasta tal punto que para la primera mitad del siglo VI d.C. tan sólo se mantienen ocupados 28 sitios, desconociéndose la realidad poblacional de la séptima centuria.

El poblamiento rural aljarafeño que aquí analizamos se ubica en los actuales términos municipales de San Juan de Aznalfarache, Tomares, Castilleja de la Cuesta, Gines, Bormujos, Mairena del Aljarafe y Gelves. Se trata de una comarca alta y amesetada situada en la margen derecha del río Guadalquivir, conformada por una base rocosa calcarenítica. Esta formación geológica de origen terciario favoreció la creación de importantes acuíferos que tienden a aflorar en ciertas zonas de la superficie a modo de fuentes y arroyadas, siendo un recurso al que tradicionalmente se ha accedido mediante sistemas de pozos. La elevación general del terreno respecto al valle fluvial, que oscila entre los 100 y 50 m.s.n.m., se ha constituido hasta el presente como un atractivo de poblamiento humano desde época prehistórica. Por otra parte, la densidad de ocupación antrópica se ve incrementada en las proximidades de cauces como el del río Pudio, el arroyo Sequillo o el arroyo de Porzuna.

En el cerro de Chavoya o de los Sagrados Corazones, en el actual municipio de San Juan de Aznalfarache, se emplazó la antigua ciudad de Osset Iulia Constantia (Escacena Carrasco, 1986). Este enclave viene a coincidir con la descripción que hizo Plinio en relación con su ubicación (NH, III, 1, $11)^{2}$, así como con las características documentadas

2 La descripción de Plinio señala que la ciudad de Osset se emplazaba al sur de Hispalis y al otro lado del Baetis, quedando igualmente al norte de Caura. Únicamente San Juan de Aznalfarache en este entorno posee estas características geográficas, pese a que otros autores hayan desea- 
en el registro arqueológico, que permiten definir el asentamiento como una urbe. Se han podido constatar en la zona nordeste del promontorio restos de la base de una torre romana elaborada mediante opus caementicium, y en relación con ella algunos tramos de muralla en dirección al edificio denominado Regina Mundi. En cambio, en la falda noroeste del cerro se ubica una necrópolis romana, encontrada gracias a unas obras realizadas en la zona. Dicha necrópolis presentaba el rito de inhumación bajo cubierta de tegulae a dos aguas, pero poco más sabemos de ella (Rodríguez González, 2002). Aparte de estas noticias, poseemos datos recopilados durante campañas de prospecciones y que constatan la presencia de abundantes restos cerámicos (fig. 2, 27-34): TSI (Consp. 14), TSG (Drag. 27, base de gálica y galbos de marmorata), TSH, TSC (Hayes 6), cerámica común romana (Vegas 16b), ánforas Haltern 70, así como restos de material constructivo (Ponsich, 1974, 30; Escacena Carrasco y Padilla Monge, 1992, 53-54)3. Todo este material ofrece una horquilla cronológica para el sitio que va desde el cambio de era hasta finales del siglo II d.C. A pesar de la datación que permite efectuar el citado material, sabemos mediante las fuentes literarias -como se comentará más adelante-, que Osset estuvo ocupada en la Antigüedad Tardía, jugando una función militar clara durante el periodo visigodo (cf. Escacena Carrasco, 1987) ${ }^{4}$.

Si se retrocede al momento primigenio de la conquista romana de la Península Ibérica, las fuentes grecolatinas guardan silencio absoluto sobre la categoría jurídica que adquiere la ciudad tras su anexión. Sí, en cambio, se sabe que adquiere el epíteto de Iulia Constantia a fines de la República romana, motivo por el que es sugerente plantear que en estos momentos es cuando adquirió este apelativo -referente a la gens Iulia-, al coincidir con la intervención de César en Hispania y quizás por haber sido dicha comunidad procesariana durante

do interpretar Salteras, Castilleja de la Cuesta o el barrio de Triana como posibles ubicaciones de esta ciudad romana ( $p$. e. Thouvenot, 1940, 726).

3 Las tipologías que aquí se anotan no vienen a coincidir con las ofrecidas por los arqueólogos que documentaron tales ejemplares cerámicos, ya que responden a una revisión crítica del aparato gráfico ofrecido por los mismos.

4 Además tenemos noticias de que en el año 2005 se efectuó una excavación arqueológica con motivo de las obras del metro, dándose a conocer una serie de estructuras de posible adscripción tardorromana. El informe de dicha intervención no ha podido ser consultado. la guerra entre éste y Pompeyo (cf. Escacena Carrasco y Padilla Monge, 1992, 54; Ordóñez Agulla y Beltrán Fortes, 2005, 25). Curiosamente, la información disponible a través de la arqueología para el territorio aledaño a Osset se circunscribe a época imperial romana, y tan sólo el Cerro de Chavoya cuenta con hallazgos algo anteriores al cambio de era. Esta escasez de información para el período republicano puede deberse a dos motivos.

En primer lugar, podría plantearse que allá donde hay ausencia de información hubo ausencia de poblamiento. Si esto fuese cierto, una posible explicación sería que la población rural, ante un contexto de hostilidad con Roma, se concentró en el núcleo ossetano, no volviéndose a desperdigar por el territorio hasta momentos muy posteriores. Ante esta situación, y una vez derrotada Osset, pudo ser Hispalis el centro de control administrativo en calidad de colonia (Garrido González, 2011, 608), lógica desde la que se han interpretado las dinámicas de otros lugares, por ejemplo el caso de Astigi (Sáez Fernández et alii, 2008, 169-170). No obstante, siguen existiendo importantes problemas que van en detrimento de esta hipótesis explicativa. Si la población rural se concentró en el enclave de Osset debería de haber dejado su impronta en el registro arqueológico de este asentamiento, y los restos cerámicos arriba descritos, así como recientes intervenciones en la zona, nos sitúan en una cronología altoimperial (Rodríguez González, 2002).

Este asunto lleva a reflexionar sobre el segundo motivo. No disponer de datos sobre la época republicana para esta zona podría ser un indicio de los problemas inherentes a la técnica de prospección arqueológica, teniendo en cuenta que los restos de fases más antiguas se encuentran por lo general a mayor profundidad. Esta causa estratigráfica hace que, mientras más bajo se halle un contexto ocupacional, decrezca la probabilidad de que el material del mismo aflore a superficie ante la acción del arado y otros factores postdeposicionales.

Desde la década de 1970 se ha venido localizando en torno a este núcleo una serie de yacimientos que nosotros sólo nos atrevemos a categorizar genéricamente como asentamientos rurales de época romana por los motivos anteriormente enunciados. Dejando a un lado la ciudad de Osset, hemos podido cuantificar un total de 36 yacimientos que, a grandes rasgos, pudieron llegar a estar ocupados durante época romana (cf. Ponsich, 1974; Escacena Carrasco, 1987; Escacena Carrasco y Padilla Monge, 

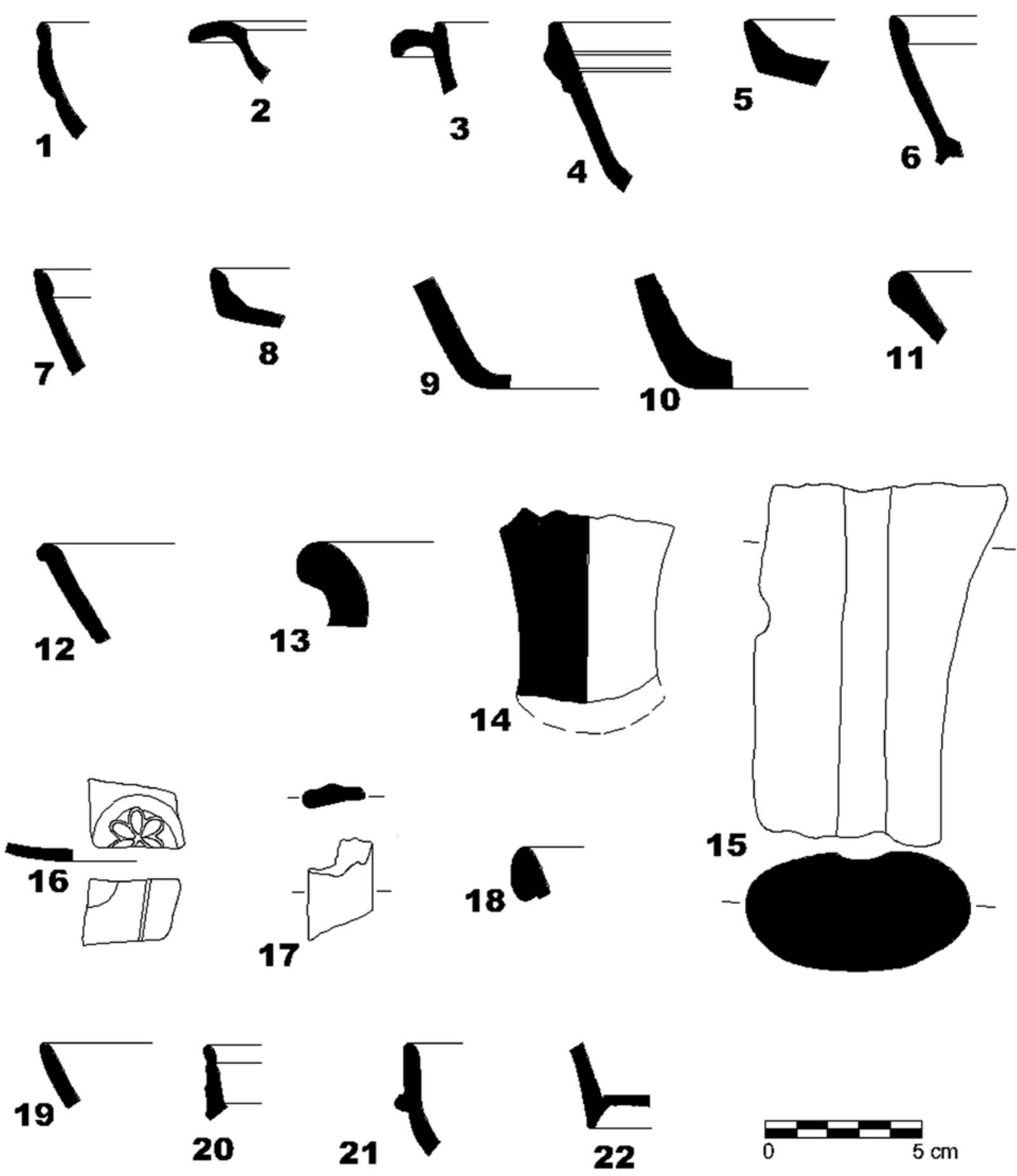

Figura 1. Materiales cerámicos de época romana procedentes de Talca de Tosa (1-3), Gelves (4), Hacienda del Carmen (5-6), La Venta Mascareta (7-8), Santo Cristo de la Mata (9-14), Aljamar (15-19) y Sandoval (20-22) (elaboración propia a partir de Ponsich, 1974 y de Escacena Carrasco y Padilla Monge, 1992). 

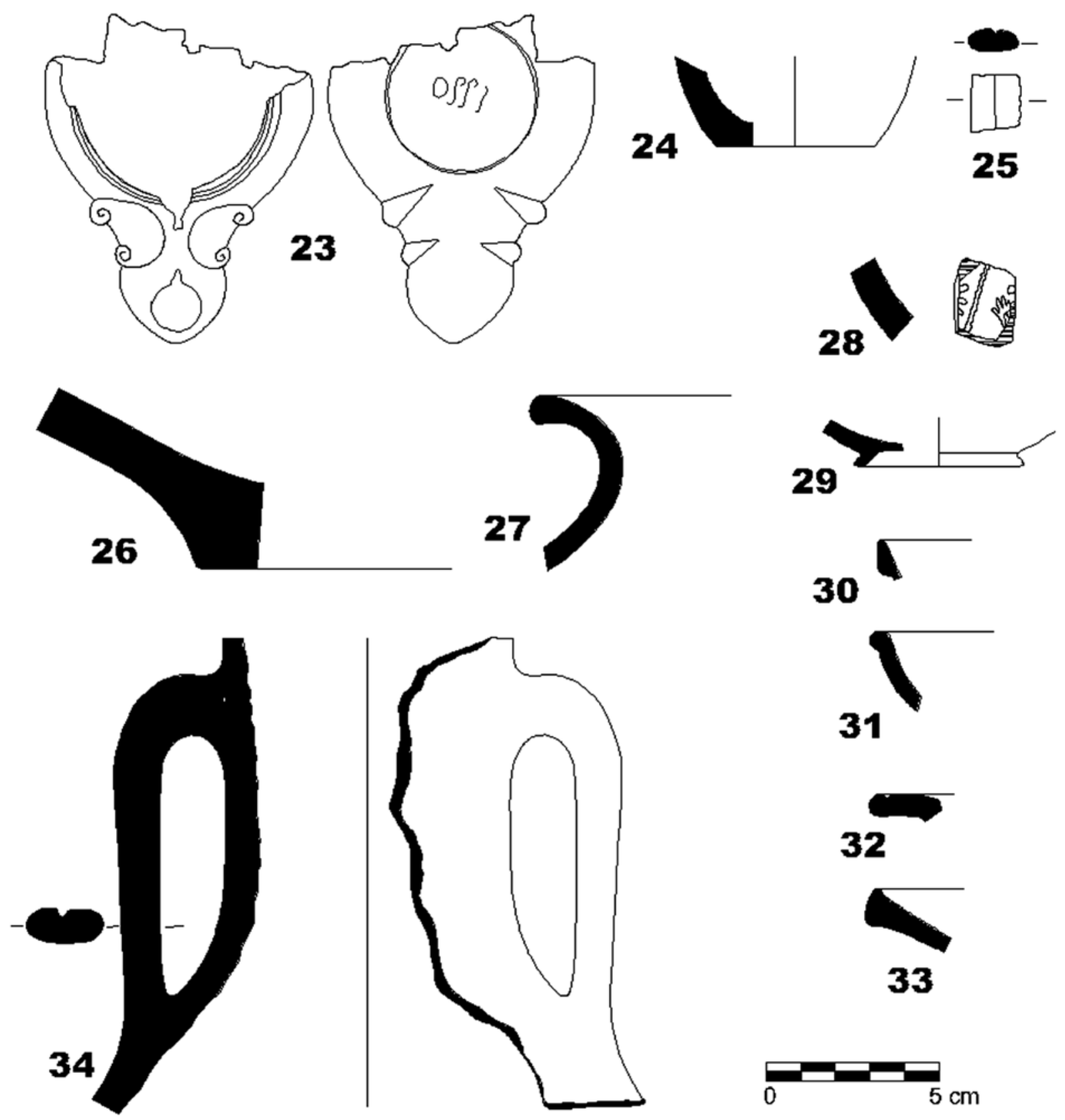

Figura 2. Materiales cerámicos de época romana procedentes de Colegio Aljarafe (23-26) y Osset (27-34) (elaboración propia a partir de Ponsich, 1974 y de Escacena Carrasco y Padilla Monge, 1992). 


\begin{tabular}{|c|c|c|c|c|c|c|c|c|}
\hline YACIMIENTOS & SIGLO I a.C. & SIGLOI & SIGLOII & SIGLO III & SIGLOIV & SIGLOV & SIGLO VI & SIGLO VII \\
\hline \multicolumn{9}{|l|}{ VALPARAISO } \\
\hline \multicolumn{9}{|l|}{ TOMARES } \\
\hline \multicolumn{9}{|l|}{ ALAMAR } \\
\hline \multicolumn{9}{|l|}{ SANTA EUFEMIA II } \\
\hline \multicolumn{9}{|l|}{ HACIENDA DEL CARMEN } \\
\hline TALCA DE TOSA & & & & & & & ¿? & \\
\hline LA VENTA MASCARETA & & & & & & ¿? & & \\
\hline IBARRA & & & & & & & ¿? & \\
\hline DOÑA ELVIRA & & & & & & ¿? & & \\
\hline \multicolumn{9}{|l|}{ EL TEAAR - EL PERRUÑo } \\
\hline \multicolumn{9}{|l|}{ LOS CÁRABOS } \\
\hline EL ROSAL & & ¿? & ¿? & & & ¿? & ¿? & \\
\hline SANTO CRISTO DE LA MATA & & & & ¿? & & & & \\
\hline BROTALA & & & & & & ¿? & & \\
\hline \multicolumn{9}{|l|}{ LA TINAIUELA } \\
\hline PORZUNA & & & & & & & ¿? & \\
\hline EL JARDINILLO & & & & ¿? & & & & \\
\hline \multicolumn{9}{|l|}{ GELVES } \\
\hline \multicolumn{9}{|l|}{ COLEGIO AUARAFE } \\
\hline \multicolumn{9}{|l|}{ CASA DE BUENA VISTA } \\
\hline \multicolumn{9}{|l|}{ LACUESTA } \\
\hline \multirow{2}{*}{\multicolumn{9}{|c|}{ MACHALAMAR }} \\
\hline & & & & & & & & \\
\hline CERRO DE LOS VILLARES & & & & & & ¿? & & \\
\hline CAZALLA ALMANZOR & & & & & & & $¿ ?$ & \\
\hline TOTAL & 0 & $13 / 14$ & $19 / 20$ & $16 / 18$ & 19 & $11 / 17$ & $3 / 8$ & 0 \\
\hline
\end{tabular}

Figura 3. Cronograma por siglos del poblamiento romano en torno a Osset.

1992; Romo Salas y Vargas Jiménez, 1997; Vargas Jiménez y Romo Salas, 1999; 2002; Ordóñez Agulla y Beltrán Fortes, 2005; Amaya Hidalgo et alii, 2010; García López, 2010; Guisado Castejón et alii, 2010; Hunt Ortiz y Cordero Ruiz, 2010; Domínguez Berenjeno y Vera Fernández, 2011). Sin embargo, nos hemos visto obligados a realizar una revisión crítica de los mismos y a seleccionar tan sólo aquéllos cuyas formas cerámicas permiten constatar tal hecho de una forma más fiable. Por ejemplo, en dicha revisión hemos dejado de lado tanto aquellos yacimientos de época romana de cronología indeterminada como aquellos otros cuya adscripción sólo viene dada por fragmentos amorfos, dado que simplemente permiten barajar horquillas cronológicas amplias que impiden valorar al detalle la evolución del poblamiento en la zona. Así, sólo se han considerado aquellos sitios con formas cerámicas definidas, ya que estas permiten afinar más el marco temporal de ocupación de los sitios (fig. 1 y fig. 2). La criba selectiva realizada a partir de dichos criterios nos ha hecho trabajar finalmente con un número de 25 yacimientos (fig. 3$)^{5}$.

Además de Osset, para el siglo I d.C. se han documentado 13 sitios (fig. 4), de los cuales uno corresponde a una necrópolis -La Cuesta- y otro a un asentamiento con alfar de materiales constructivos -Cerro de los Villares- (Chic García y García Vargas, 2004), mientras que el resto son asentamientos rurales. El Cerro de los Villares (Bormujos) es la única figlina de esta zona constatada hasta el momento, concentrándose la mayor parte de la alfarería romana del Bajo Guadalquivir en torno a Hispalis, Orippo e Italica. El yacimiento de La Cuesta puede interpretarse como una zona funeraria a razón de los hallazgos casuales allí efectuados, así como de los materiales provenientes de este lugar, y que

5 Se han excluido del estudio los siguientes enclaves arqueológicos: Castilleja de la Cuesta, Cortijo del Cañuelo, Gines, Hacienda Simón Verde, Palomares del Río, Repudio, Santa Eufemia 1, Santo Domingo, Torrequemada A y B y Zaudín Bajo. 


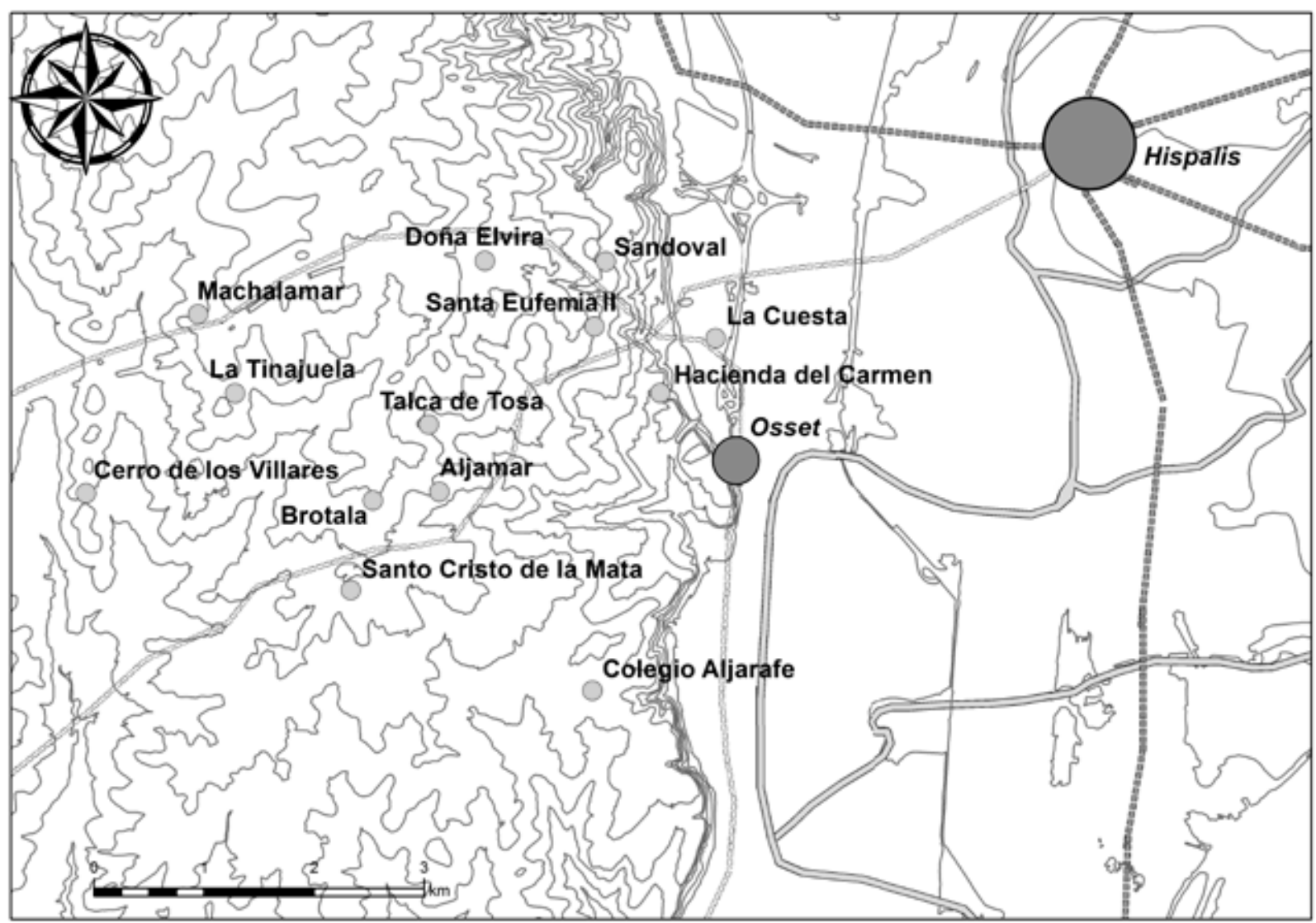

Figura 4. Siglo I d.C.

ya hemos analizado de forma pormenorizada en otro trabajo (Gómez Peña et alii, 2011, 82-93). Por otra parte, cabe igualmente la posibilidad de interpretar los cercanos sitios de Valparaiso y Hacienda Simón Verde como necrópolis, al menos para el primer caso asociada a un asentamiento rural. Los epígrafes funerarios hallados en ellos, CIL II, 1257 (=CILA II, 588) y CIL II, 1256 (= CILA II, 586), fueron en su día interpretados por J. L. Escacena Carrasco y A. Padilla Monge (1992, 50-52) como material de acarreo posiblemente proveniente del entorno del cerro de Chavoya. Sin embargo, tanto por la cercanía a un camino secundario como por la importante presencia de tégulas en este complejo arqueológico, no vemos disparatada la hipótesis de una posible área funeraria para el lugar.

La evidencia de 13 ó 14 asentamientos rurales para la primera centuria de nuestra era quizás deba ponerse en conexión con un periodo de relativa estabilidad en la dinámica fluvial. Esto sin duda contribuyó a agilizar los intercambios y exportaciones de productos agropecuarios y mineros en el occidente de la Bética. Del mismo modo, la implantación de colonos en otras zonas del Bajo Guadalquivir que desde época cesariana y augustea venía produciéndose, debió fijar las bases para que la red de asentamientos rurales creciese en otras zonas en principio ajenas al territorio de las colonias, pero sobre las que debieron poner sus ojos tales propietarios en un marco económico general en el que interesaba incrementar la producción agrícola para abastecer la demanda estatal. Este interés por parte de los particulares puede ponerse en conexión con la necesidad de obtener recursos dentro de una dinámica de evergetismo ciudadano. De hecho, a finales del siglo I d.C. el estado romano trató de impulsar una serie de medidas con la finalidad de potenciar la agricultura y la ganadería (Chic García, 2009a; 2009b; Garrido González, 2011, 596).

En el siglo II d.C. los asentamientos ascienden a 19 ó 20 (fig. 5), siendo el momento de mayor densidad en cuanto a entidades rurales se refiere junto al siglo IV d. C. En otras zonas distintas a nuestra área de estudio es normal la constatación de la tendencia inversa, pues suele haber más asentamientos en la primera centuria que en la segunda. En el entor- 


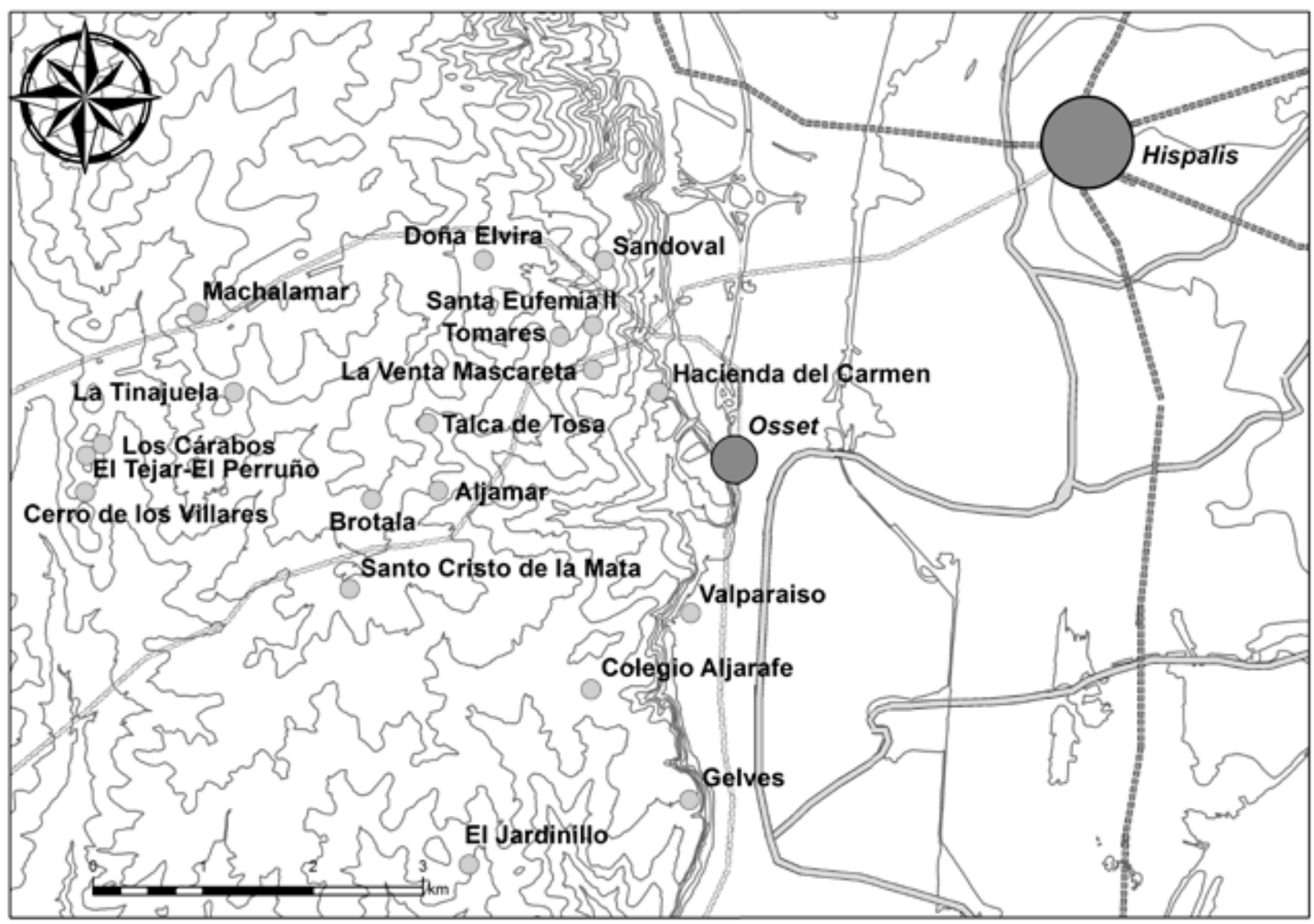

Figura 5. Siglo II d.C.

no de Carmona, por ejemplo, se han cuantificado 206 sitios arqueológicos para el siglo I d.C., mientras que para el II d.C. la cantidad desciende a 191 (Conlin Hayes, 2012, 46). Algo parecido ocurre en la zona de la campiña de Marchena, donde se han constatado 100 asentamientos rurales para la primera centuria frente a los 74 de la segunda (García Vargas et alii, 2002). En cambio, si se observa el margen derecho del Baetis durante esta centuria, se aprecia en términos generales cómo el Aljarafe ha experimentado una evolución distinta. Tanto las prospecciones realizadas por P. Garrido González (2011) en la zona del Guadiamar como los estudios sobre la Itálica del siglo II d.C. (Caballos Rufino et alii, 2006) apuntan hacia un aumento poblacional para esta comarca. ¿Qué pudo contribuir a que el poblamiento se incrementase en la segunda centuria? S. Ordóñez Agulla $(2005,112)$ entiende que "el papel de la política atlántica emprendida desde época de César y continuada hasta inicios del siglo II d.C. es un factor fundamental para entender la gran proyección de Hispalis durante las dos primeras centurias de la era”. En consonancia con estos profundos cambios se aprecia una transformación en las comarcas adyacentes a Sevilla hacia un modelo disperso y dejando a un lado los hábitats concentrados (Ordóñez Agulla, 2005). Por los datos arqueológicos parece ser que en Osset el despliegue se inicia en el siglo primero, pero es en el segundo cuando más se fortalece.

Por su parte, en la tercera centuria de nuestra era se mantuvieron en activo 16 de los yacimientos documentados, pudiendo ascender la cifra a 18 de terminar corroborándose la continuidad poblacional de El Jardinillo y del Santo Cristo de la Mata (cf. Escacena Carrasco y Padilla Monge, 1992; Hunt Ortiz y Cordero Ruiz, 2010). Para este siglo existen ya claras evidencias sobre la ocupación de El Rosal ${ }^{6}$, con lo que incluso barajando la cifra más negativa el descenso ocupacional fue mínimo (fig. 6). En relación con este leve descenso podría

6 La cronología de este yacimiento ha sido matizada por nosotros al combinar la información de los materiales que sus excavadores detallan para cada unidad estratigráfica con la matriz de Harris aportada (cf. Vargas Jiménez y Romo Salas, 2002). 


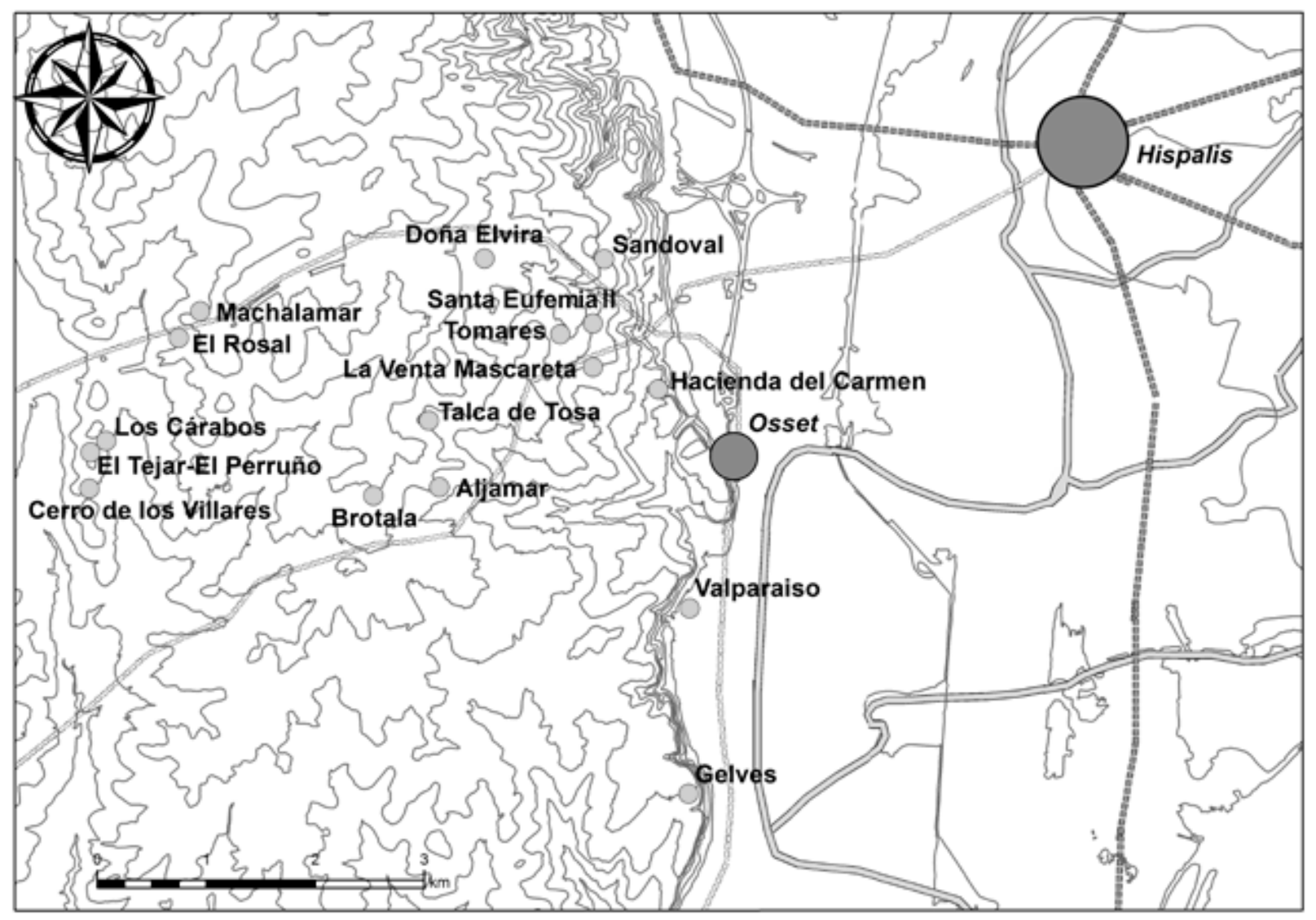

Figura 6. Siglo III d.C.

hacerse mención a dos procesos históricos bien constatados. Por una parte el hundimiento de la minería de la plata a finales del siglo II d.C., hecho que afectó directamente a las comarcas extractivas de la Faja Pirítica Ibérica e indirectamente a zonas interrelacionadas con tales territorios mineros, como pudo ser el caso de parte del Aljarafe (Chic García, 2005). De otro lado, la llegada al poder imperial de la dinastía de los Severos tuvo lugar tras una guerra civil que afectó notoriamente a las provincias de Hispania. Importantes sectores de las oligarquías béticas del olivar se alinearon del bando de Clodio Albino, enemigo de Septimio Severo. Cuando este último ganó la guerra, no sólo se encargo de liquidar a muchos de los partidarios de sus enemigos, sino que confiscó un número importante de propiedades que pasaron a formar parte de la res priuata imperial y a ser administradas por el procurator ad Kalendarium Vegetianum (Remesal Rodríguez, 1996, 196 y 211). Es posible que esta reestructuración incidiera en el abandono de algún que otro asentamiento rural de la zona aquí estudiada.
De ser abandonado en el siglo III d. C., los materiales registrados en el yacimiento de El Jardinillo indican una reocupación del lugar para el siglo IV d.C. (Hunt Ortiz y Cordero Ruiz, 2010). No sería este el caso del Santo Cristo de la Mata, que de llegar a perdurar hasta la tercera centuria no trascendió a las siguientes. Además de ello se deshabitó Valparaiso y comenzaron a ocuparse tres nuevas entidades rurales: Ibarra, La Tinajuela y Porzuna. De este modo, el siglo IV d.C. se conforma como una de las centurias con mayor densidad de yacimientos arqueológicos rurales para el área ossetana, con un total de 19 (fig. 7). Si se compara esta zona de estudio con las campiñas al sur del Guadalquivir (García Vargas y Vázquez Paz, 2012) se observarán tendencias divergentes al respecto, puesto que mientras que en una zona el número de asentamientos aumenta sensiblemente, en la otra decrece. Ello podría ponerse en relación con una progresiva pérdida de navegabilidad del Guadalquivir aguas arriba de Hispalis, yendo esto en detrimento de la funcionalidad económica de algunos de estos sitios y en beneficio de la parte oriental del Aljarafe más próxima a la capital hispalense. En este 


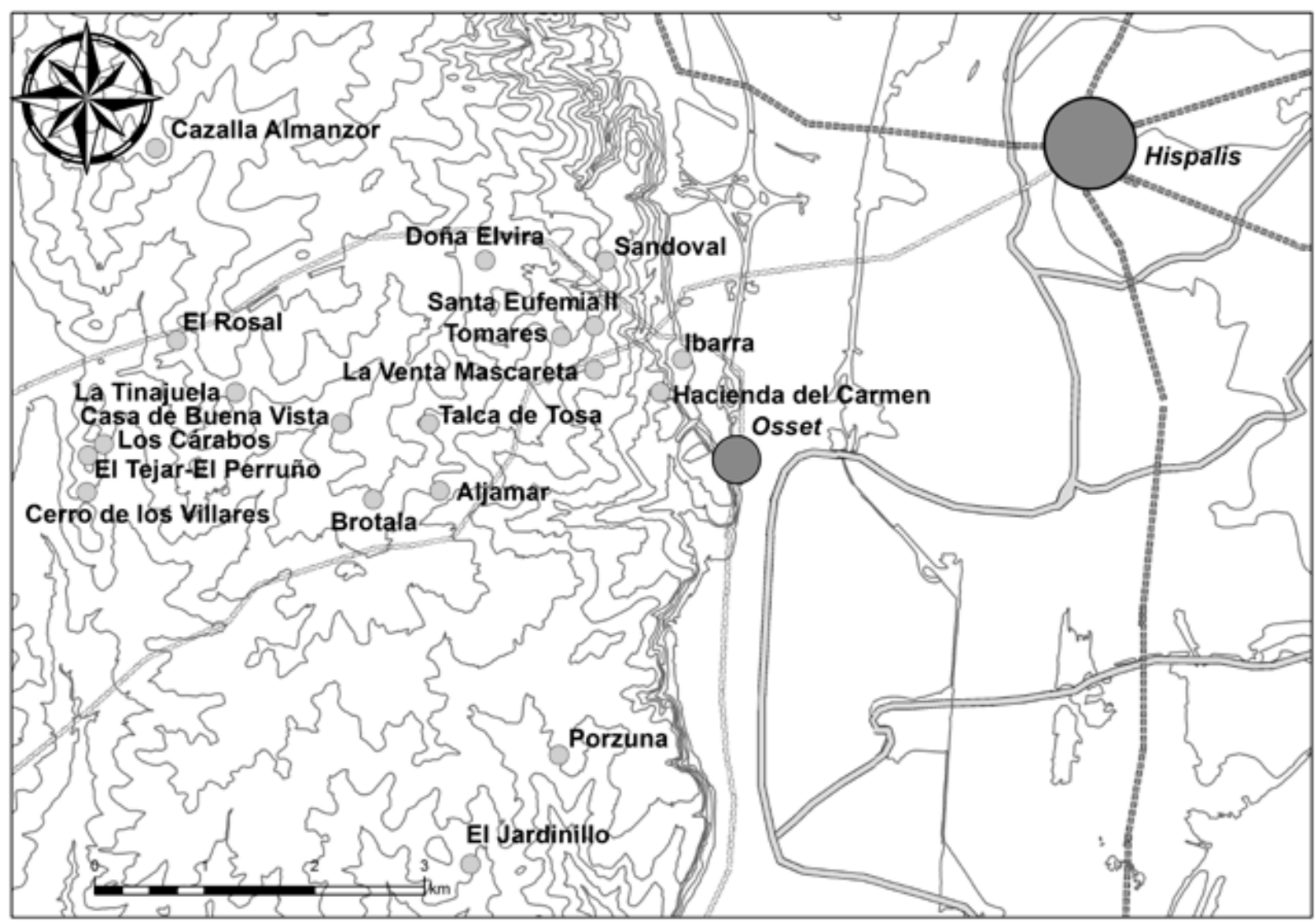

Figura 7. Siglo IV d.C.

sentido, pensamos que se dieron una serie de circunstancias que potenciaron este hecho.

Primero, el tramo fluvial que transcurría desde Hispalis hasta la desembocadura del Baetis no vio tan mermada su navegabilidad, con lo que dicho trayecto del río se mantuvo más viable comercialmente. Ello no sólo queda avalado por los estudios geoarqueológicos, sino por las referencias históricas posteriores. Así, el geógrafo andalusí AlIdrîsî describió para el siglo XII una ruta marítimo-fluvial que conectaba el Mediterráneo islámico con Ishbîliya a través del wadi al-Kabir (Mizal, 1989). No debe de extrañar, por tanto, que durante la Antigüedad Tardía el citado tramo mantuviera vitalidad comercial, no sólo a nivel de importación de productos norteafricanos y del Mediterráneo oriental, sino que también es probable la comercialización de productos aljarafeños a otras zonas de la Baetica occidental e incluso su exportación a otras partes del Imperio (Remesal Rodríguez, 1991).

En segundo lugar, el territorio analizado se encuentra próximo a dos importantes urbes del momento, Hispalis y Osset, quedando en la misma margen derecha del Guadalquivir y un poco más abajo de esta última la ciudad de Caura. A modo de hipótesis de trabajo podría sostenerse la posibilidad de un incremento en la demanda de provisiones del campo ossetano, destinados por una parte al comercio regional y comarcal, y, de otro lado, al abastecimiento de las comunidades locales de los núcleos urbanos más próximos.

Por último, el área estudiada no sólo quedaba bien comunicada mediante el Baetis. Una serie de vías o caminos secundarios interconectaban los distintos asentamientos rurales con las ciudades indicadas (Escacena Carrasco, 1982; Escacena Carrasco y Padilla Monge, 1992). Esta red debió vertebrar las conexiones existentes entre los nodos rurales y los urbanos a nivel local. Además de ello, tales vías de comunicación terrestre funcionaron focalizando el poblamiento rural del entorno. En el mapa de la figura 6 puede apreciarse cómo los distintos sitios arqueológicos suelen distar entre los 200 y 800 metros respecto a los caminos secundarios. Tanto es así que existe una peculiar concentración poblacional en la encrucijada habida al noroeste de Osset. 


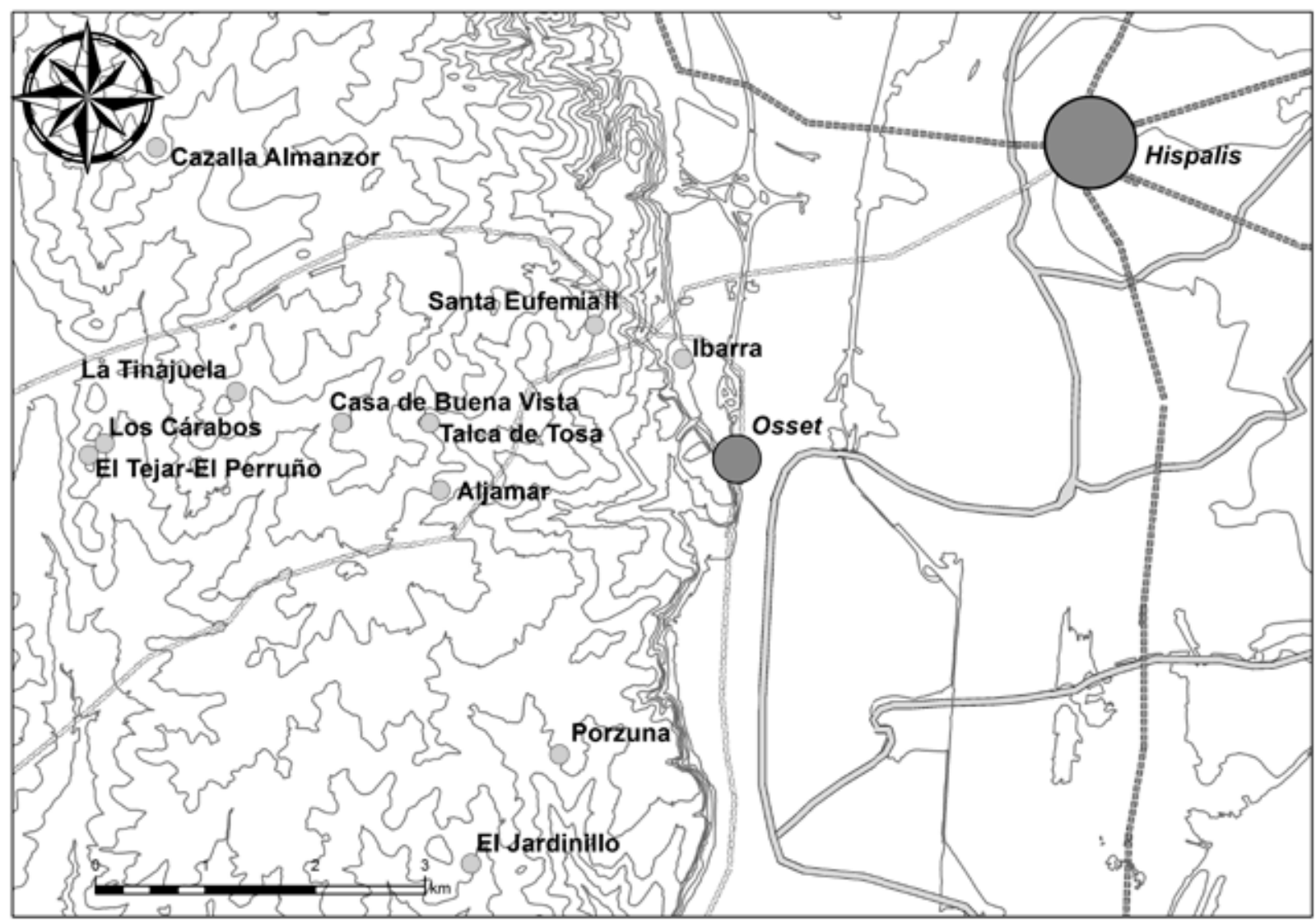

Figura 8. Siglo V d.C.

Estos y otros tantos factores debieron contribuir a que las comunidades que en el siglo IV d.C. poblaron el territorio ossetano no redujeran la cantidad de hábitats rurales en comparación con otras zonas, sino que creciera su número en relación con la centuria anterior.

En el siglo $\mathrm{V}$ d.C. se abandonaron los núcleos de Hacienda del Carmen y Tomares, siendo posible igualmente la desocupación de La Venta Mascareta, Doña Elvira, El Rosal, Brotala, Sandoval y Cerro de los Villares. Si tenemos sólo en cuenta los primeros datos anotados, más certeros, tendríamos en activo un total de 17 entidades, mientras que si barajamos la posibilidad de abandono de los asentamientos de dudosa ocupación, la cifra descendería a 11 (fig. 8). Independientemente de ello, si se comparan otra vez tales datos con los obtenidos en las campiñas al sur del Guadalquivir (García Vargas y Vázquez $\mathrm{Paz}, 2012$ ) se tiene que la contracción poblacional fue relativamente leve para esta parte del Aljarafe sevillano. Entre otras cuestiones, ello debe ponerse nuevamente en conexión con la demanda de bastimentos que las cercanas ciudades debieron ejercer.
Desde el registro arqueológico poco puede decirse de los últimos siglos de la Antigüedad Tardía para este área del reborde oriental del Aljarafe (siglos VI y VII d.C.). Quizás en ello intervengan factores metodológicos inherentes al conocimiento de las producciones cerámicas de estos momentos, así como a la calidad de la información disponible, parca o de poca fiabilidad. Pese a ello, para comprender la escasez de datos no debe perderse de vista la desaparición del fenómeno villático a lo largo del siglo $\mathrm{V}$ d.C. como un proceso que afectó a amplias zonas del occidente tardoantiguo (Chavarría Arnau, 2007). Sabemos que en la Península Ibérica el poblamiento rural tendió a concentrarse estratégicamente en ciertos lugares, dando origen con el tiempo a la eclosión aldeana que terminó caracterizando al territorio altomedieval europeo (Quirós Castillo y Bengoetxea Rementería, 2011), teniendo en $A l$-Andalus su expresión a través de las qurà (Pérez-Aguilar, 2013). Aún así, y todavía más para la zona que nos compete, tales planteamientos deben todavía ser bien investigados desde la arqueología. 


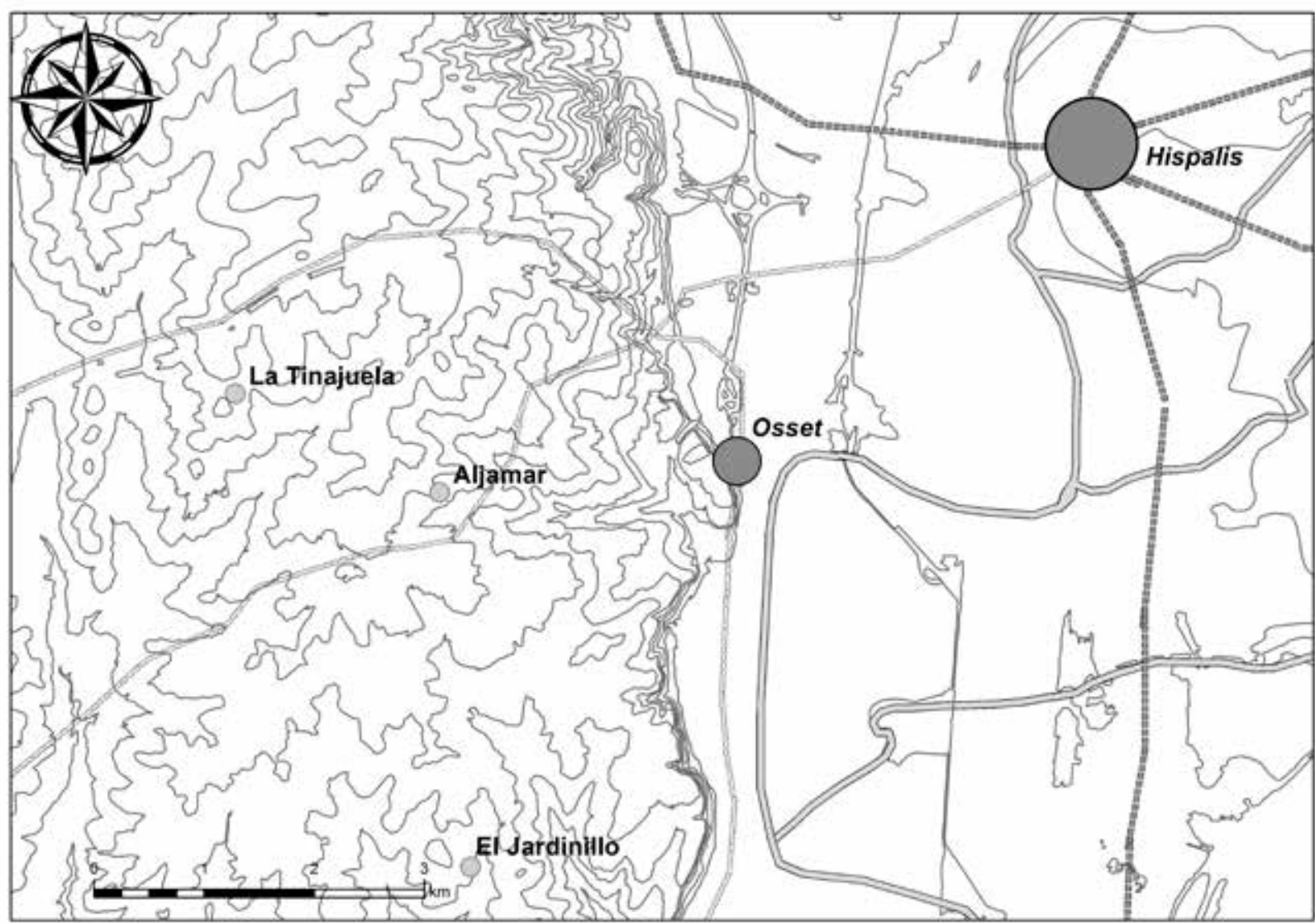

Figura 9. Siglo VI d.C.

Ante tal problemática, la actividad de los núcleos urbanos más próximos al territorio analizado nos podría hacer pensar que la red de relaciones existente entre las ciudades y los asentamientos rurales debió de mantenerse, aunque quizás de forma reestructurada. Para el caso de Hispalis, las excavaciones en la Plaza de la Encarnación han permitido registrar un importante repertorio anfórico tardoantiguo en el que predominan los ejemplares provinciales y lusitanos, existiendo también abundantes ánforas orientales y africanas. Dicho conjunto abarca un amplio margen cronológico que va desde la segunda mitad del siglo III d.C. a comienzos del VI d.C. (Amores Carredano et alii, 2007). A dicho conjunto cerámico habría que añadir la presencia de sigillata africana en las variantes A, C y D, vajilla de mesa chipriota e incluso de importante material marmóreo (González Acuña, 2011). Por otra parte, las intervenciones en la cisterna altoimperial de la Plaza de la Pescadería han documentado, asociadas a los niveles de su colmatación, importaciones de mediados del siglo VI d.C. compuestas por vajilla de mesa africana, ánforas, así como cerámica común y de cocina (Maestre Borge et alii, 2010; Vázquez Paz y García Vargas, 2011).

Para el caso de Osset, las fuentes escritas nos informan de la relevancia geoestratégica que la ciudad jugó, junto a Itálica (Santiponce), en el cerco a Hispalis por parte del rey godo Leovigildo entre los años 583 y 585 dentro de la contienda librada contra su hijo Hermenegildo (cf. García Moreno, 2001; Collins, 2005; Díaz Martínez et alii, 2007). El hijo rebelde posicionó su centro de operaciones en Hispalis, con lo que para aproximarse a dicha ciudad el monarca toledano tuvo que llevar a cabo una serie de movimientos estratégicos entre los que se encontraba el control de Osset y su entorno inmediato. La tenencia de esta urbe permitía al rey cortar el acceso a Hispalis vía fluvial desde el sur, restándole al enemigo el apoyo de la aliada flota bizantina. El dominio del territorio ossetano e italicense le permitía igualmente inclinar la balanza a su favor, impidiendo al bando de Hermenegildo la llegada de víveres del cercano Aljarafe. Los datos de dicha contienda nos informan indirectamente sobre la relevancia económica que quizás seguía teniendo 
nuestra zona de estudio y que su producción agropecuaria debió ser demandada por las comunidades urbanas más próximas también en la segunda mitad del siglo VI d.C.

De ser así, y en función del conocimiento arqueológico que a día de hoy disponemos, sí podemos apuntar hacia la existencia de una reestructuración del paisaje humano para esta centuria. Con cierta certeza podemos hacer referencia a la ocupación de tan sólo 3 asentamientos rurales: El Jardinillo, La Tinajuela y Aljamar. Sin embargo, cabe la posibilidad de que el número pudiera elevarse a 8 de estar habitados los sitios de El Rosal, Porzuna, Ibarra, Talca de Tosa y Cazalla Almanzor, aunque tenemos ciertas dudas al respecto (fig. 9). Haciendo nuevamente un ejercicio comparativo, se observa cómo el descenso poblacional fue importante. Sin embargo, si tenemos en cuenta el zoom con el que estamos observando este territorio podemos inferir que esta tendencia poblacional fue más suave que en otras zonas (García Vargas y Vázquez Paz, 2012).

\section{CONCLUSIONES}

Resumiendo lo hasta ahora dicho, podemos sostener que tanto la cercanía a estos núcleos urbanos como la existencia de una red secundaria de comunicación terrestre y fluvial permiten comprender cómo el poblamiento de este entorno rural concreto hizo ascender el poblamiento en los siglos I-II d.C. y que no declinase en demasía durante la Tardoantigüedad. Al compararse tales datos con los de otras áreas del Bajo Guadalquivir puede deducirse que tales asentamientos rurales fueron beneficiados en el marco de un proceso en el que mantuvieron con relativo éxito su predisposición para abastecer de recursos al menos a las comunidades humanas locales. Todavía queda mucha investigación por delante y numerosos problemas que resolver, como por ejemplo los relativos al periodo republicano y al vacío de información documentado en el siglo VII d.C. o las razones ecológicas que hay detrás de la reestructuración poblacional del VI d. C. Lo deseable sería ir comparando esta muestra poblacional con las dinámicas de otras zonas del Bajo Guadalquivir, hecho que permitiría refinar o rectificar el análisis aquí esbozado.

\section{Bibliografía}

Abad Casal, L. (1975), El Guadalquivir, vía fluvial romana, Sevilla.

Amaya Hidalgo, R., Mena-Bernal Rosales, I. y Sar- dá Piñero, D. (2010), “Actividad arqueológica preventiva en el yacimiento inventariado "Aljamar III" (Tomares, Sevilla)", Anuario Arqueológico de Andalucía, 2006, 4224-4229.

Amores Carredano, F., García Vargas, E. y González Acuña, D. (2007), “Ánforas tardoantiguas en Hispalis (Sevilla, España) y el comercio mediterráneo", LRCW2. Late Roman Coarse Wares, Cooking Wares and Amphorae in the Mediterranean. Archaeology and Archaeometry, Vol. I, Oxford, 133-146.

Arteaga Matute, O., Schulz, H. D. y Roos, A. M. (1995), “El problema del 'Lacus Ligustinus'. Investigaciones geoarqueológicas en torno a las Marismas del Bajo Guadalquivir”, Tartessos 25 años después, 1968-1993, Jerez de la Frontera, 99-135.

Barral Muñoz, M. A. (2009), Estudio geoarqueológico de la ciudad de Sevilla. Antropización y reconstrucción paleogeográfica durante el Holoceno Reciente, Sevilla.

Caballos Rufino, A., Martin Fatuarte, J. y Rodríguez Hidalgo, J. M. (2006), Itálica arqueológica, Sevilla.

Chavarría Arnau, A. (2007), El final de las villae en Hispania (siglos IV-VII d.C.), Turnhout.

Chic García, G. (2005), "Marco Aurelio y Cómodo. El hundimiento de un sistema económico", $L a$ Hispania de los Antoninos (98-180), Actas del II Congreso Internacional de Historia Antigua, Valladolid, 567-586.

Chic García, G. (2009a), El comercio y el Mediterráneo en la Antigüedad, Madrid.

Chic García, G. (2009b), "Al César lo que es del César. La producción de metales en Riotinto en época romana”, Rio Tinto: Historia, Patrimonio Minero y Turismo Cultural, Huelva, 95114.

Chic García, G. y García Vargas, E. (2004), “Alfares y producciones cerámicas en la provincia de Sevilla. Balance y perspectivas", Actas del Congreso Internacional Figlinae Baeticae. Talleres alfareros y producciones cerámicas en la Bética romana (ss. II a. C. - VII d. C.), Vol. I, Oxford, 279-348.

Collins, R. (2005), La España visigoda, 409-711, Barcelona.

Conlin Hayes, E. (2012), “Aproximación al mundo rural romano en el territorio de Carmo”, Romula, 11, 27-57.

Delgado Bujalance, B. (2004), Cambio de paisaje 
en el Aljarafe durante la segunda mitad del siglo $X X$, Sevilla.

Díaz Martínez, P. C., Martínez Maza, C. y Sanz Huesma, F. J. (2007), Hispania tardoantigua y visigoda, Madrid.

Domínguez Berenjeno, E. L. y Vera Fernández, A. (2011), "Actividad Arqueológica Preventiva: Carta Arqueológica del término municipal de Tomares (Sevilla)", Anuario Arqueológico de Andalucía, 2005, 3001-3018.

Escacena Carrasco, J. L. (1980), Contribución a la Carta Arqueológica del Guadalquivir: los Rebordes Ribereños del Aljarafe y Los Alcores, Tesis de Licenciatura inédita, Sevilla.

Escacena Carrasco, J. L. (1982), "Antiguas vías de comunicaciones en el Bajo Guadalquivir”, $G a$ des, 9, 129-153.

Escacena Carrasco, J. L. (1986), "OSSET IVLIA CONSTANTIA: San Juan de Aznalfarache (Sevilla)", Habis, 17, 539-547.

Escacena Carrasco, J. L. (1987), "Yacimientos arqueológicos de época medieval en el flanco oriental del Aljarafe", Actas del II Congreso de Arqueología Medieval Española, 2, 579-587.

Escacena Carrasco, J. L., y Padilla Monge, A.(1992), El poblamiento romano en los márgenes del antiguo estuario del Guadalquivir, Écija.

García López, G. (2010), “Actividad arqueológica preventiva "Prospección Arqueológica Superficial en el yacimiento 'La Venta"' (Tomares, Sevilla)”, Anuario Arqueológico de Andalucía, 2006, 4655-4661.

García Moreno, L. A. (2001), "Carmona en tiempos visigodos (ss. V-VIII)", Carmona romana. Actas del II Congreso de Historia de Carmona, Carmona (Sevilla), 491-506.

García Vargas, E., Oria Segura, M. y Camacho Moreno, M. (2002), "El poblamiento romano en la Campiña sevillana: el término municipal de Marchena”, Spal, 11, 311-340.

García Vargas, E. y Vázquez Paz, J. (2012), "El poblamiento rural en las campiñas al sur del Guadalquivir durante la Antigüedad Tardía (siglos IV-VI d.C.)", Visigodos y Omeyas. El territorio, Mérida, 235-261.

Garrido González, P. (2011), La ocupación romana del Valle del Guadiamar y la conexión minera, Sevilla.

Gómez Peña, A., Pérez-Aguilar, L.-G. y Ruiz Prieto, E. (2011), Historia de Tomares: de la prehistoria reciente a la edad contemporánea,
Tomares.

González Acuña, D. (2011), Forma urbis hispalensis: el urbanismo de la ciudad romana de Hispalis a través de los testimonios arqueológicos, Sevilla.

Guisado Castejón, F., Vera Fernández, A. y Sardá, D. (2010), "Prospección arqueológica superficial y revisión de yacimientos catalogados en el término municipal de Gelves, Sevilla”, Anuario Arqueológico de Andalucía, 2004, III-2, 3300-3305.

Hunt Ortiz, M. A. y Cordero Ruiz, T. (2010), "Prospección arqueológica en la zona central-sur del término municipal de Mairena del Aljarafe (Sevilla): el yacimiento de época romana de El Jardinillo”, Anuario Arqueológico de Andalucía, 2004.2, Sevilla, 1127-1136.

Maestre Borge, C., García Vargas, E., Vázquez Paz, E. y García García, M. A. (2010), "Contextos de mediados del siglo VI d.C. procedentes de la colmatación de una cisterna romana de Hispalis (Sevilla, España)", LRCW3. Late Roman Coarse Wares, Cooking Wares and Amphorae in the Mediterranean. Archaeology and Archaeometry. Comparison between western and eastern Mediterranean, Vol. I., Oxford, 183-192.

Mizal, J. A. (1989), Los caminos de Al-Andalus en el siglo XII, Madrid.

Ordóñez Agulla, S. (2005), "Hispalis. Perfil histórico", La catedral en la ciudad (I): Sevilla, de Astarté a San Isidoro, Sevilla, 101-139.

Ordóñez Agulla, S. y Beltrán Fortes, J. (2005), "Panorama de la romanización en la comarca del Aljarafe", Aljarafe-Marismas: Actas II. Jornadas de Historia Sobre la Provincia de Sevilla (6 y 7 de mayo de 2005, Aznalcázar, Sevilla), Sevilla, 21-55.

Pérez-Aguilar, L.-G. (2013), "Problemas metodológicos en el estudio del mundo rural andalusí", Medievalista Online, 14. Página web consultada a 13/01/2014:

[http://www2.fcsh.unl.pt/iem/medievalista/ MEDIEVALISTA14/aguilar1406.html].

Ponsich, M. (1974), Implantation rurale Antique sur le Bas-Guadalquivir, Madrid.

Quirós Castillo, J. A. y Bengoetxea Rementería, B. (2011), Arqueología (III). Arqueología Medieval y Posmedieval, Madrid.

Remesal Rodríguez, J. (1991), "El aceite bético durante el Bajo Imperio”, Antigüedad y Cristia- 
nismo, 8, 355-361.

Remesal Rodríguez, J. (1996): “Mummius Secundinus. El Kalendarium Vegetianum y las confiscaciones de Severo en la Bética (HA Severus 12-13)", Gerión, 14, 195-221.

Rodríguez González, G. (2002), "Seguimiento arqueológico en la barriada de Nuestra Señora del Loreto, San Juan de Aznalfarache, Sevilla”, Anuario Arqueológico de Andalucía, 1999, vol.III-2, 1054-1061.

Romo Salas, A. S., y Vargas Jiménez, J. M. (1997), "Prospección arqueológica y diagnosis en el área residencial El Zaudín (Bormujos, Sevilla)”, Anuario Arqueológico de Andalucía, 1993, vol.III, 646-654.

Sáez Fernández, P., Ordóñez Agulla, S. y GarcíaDils, S. (2008), "Colonias romanas y municipalización flavia. ¿Conflicto de intereses?”, El territorio de las ciudades romanas (Mangas, J. y Novillo, M.A.), Madrid, 155-175.

Thouvenot, R. (1940), Essai sur la province romaine de Bétique, Paris.

Vargas Jiménez, J. M. y Romo Salas, A. (1999), "Un conjunto de materiales tardíos (siglos V-VI d.C.) en la Tinajuela (Bormujos, Sevilla)", Anuario Arqueológico de Andalucía, 1994, vol. III, 462-471.

Vargas Jiménez, J. M. y Romo Salas, A. (2002), "Evidencias arqueológicas de una villa romana en el Rosal (Bormujos, Sevilla)”, Anuario Arqueológico de Andalucía, 1999, vol.III, 975992.

Vázquez Paz, J. y García Vargas, E. (2011), "Sigillatas africanas y orientales de mediados del VI d.C. procedentes de los rellenos de colmatación de una cisterna de Hispalis (Sevilla). Los contextos de la Plaza de la Pescadería”, $L R F W 1$. Late Roman Fine Wares. Solving problems of typology and chronology. A review of the evidence, debate and new contexts, Oxford, 87-97. 